ISSN 1810-3030 (Print) 2408-8684 (Online)
Journal home page: http://baures.bau.edu.bd/jbau, www.banglajol.info/index.php/JBAU

\title{
Microbial Assessment of Chevon of Black Bengal Goat
}

\section{S. Parvin, H. M. Murshed, M. M. Hossain and M. Khan}

Department of Animal Science, Bangladesh Agricultural University, Mymensingh-2202, Bangladesh

\begin{tabular}{|c|c|}
\hline ARTICLE INFO & Abstract \\
\hline $\begin{array}{l}\text { Article history: } \\
\text { Received: } 12 \text { October } 2017 \\
\text { Accepted: } 21 \text { November } 2017\end{array}$ & \multirow{3}{*}{$\begin{array}{l}\text { This study was conducted to assess the microbial load of Black Bengal goat meat during handling and } \\
\text { selling in different markets of Mymensingh, Bangladesh. Total } 27 \text { samples were collected from three } \\
\text { different places of the city, including KR market, Seshmore and Mesua Bazar. These samples were } \\
\text { subjected to determine Total Viable Count (TVC), Total Coliform Count (TCC) and Yeast Mold Count } \\
\text { (YMC) by using standard protocols. In raw meat, mean value of TVC were highest in Seshmore market } \\
\text { ( } 5.24 \pm 0.42 \text { log cfu/g) at } 0 \text { hour but having no significant differences with other two places. In case of TCC } \\
\text { and YMC highest count were in meat of Mesua Bazar. In case of TCC, difference were observed (P }<0.05) \\
\text { among the markets. At } 5 \text { hours all the bacterial counts were increased having significant differences with } \\
\text { the initial count and in most of the cases the bacterial count crossed the acceptable limit. This was may be } \\
\text { due to the unhygienic practices of butchers. Consumers were not conscious. Suggestion has been given to } \\
\text { improve the knowledge on hygiene among the meat producers to reduce microbial load. }\end{array}$} \\
\hline $\begin{array}{l}\text { Keywords: } \\
\text { Goat, Meat, Microbial Count, } \\
\text { Quality }\end{array}$ & \\
\hline & \\
\hline
\end{tabular}

\section{Introduction}

Goat is the animal of developing countries where more than $95 \%$ of goats are reared in Asia and Africa (Chowdhury and Mutalib, 2003). At present, the approximate number of goats is 25.611 million in Bangladesh (DLS, 2016). As a source of animal protein, goat meat has for long occupied a special place in the diet for a variety of reasons including taste preference, prestige, religion, tradition and availability. Meat is an important edible post-mortem component originating from the live animals that are used as food by human. These animals include domesticated cow, buffalo, sheep, goat, camels and some wild animals i.e. dear, hog and rabbit. In addition, poultry have become a major meat producing species, while various game animals and birds provide a substantial amount of meat particularly in localized areas. However, cow, buffalo, sheep and goat are the main sources of red meat in Asia. Goat meat is without a doubt one of the staple red meat in human diet. Indeed goat meat is acceptable throughout the world but cultural and social tradition and economic condition often influence consumer preferences. Meat was the first important food that met up the hunger of ancient people living in cave (Haque et al., 2008). It plays a very vital role in keeping the human body strong in order to provide energy, health and vigor (Rahman, 2000). But, microorganisms present in meat may be harmful for human and may cause spoilage and may be used as an indicator organism. Many researchers have isolated and identified heterogeneous types of micro flora from fresh meat (Brahmbhatt and Anjaria, 1991).

Goat meat has an immense market potential, as it can becomes an ideal choice for health conscious consumers (Carlucci et al., 1998). In recent time, market of meat has been adapting to different requirements of contemporary consumers, insisting of lean and easily digestible meat of high quality and good taste (Lesiak et al., 1997). The consumer expects the meat he purchases to be safe and wholesome. Wholesome meat is produced hygienically, pathogen free, retains its natural state and nutritive value, has optimum fat and is unconditionally acceptable to the consumer (Bhandare, 2007). However, Bangladesh is a tropical country, with ambient temperatures conducive to the growth of microorganisms, which can rapidly render the meat unsafe for human consumption. Episodes of food borne diseases are reported in the press on many occasions, but due to lack of a surveillance network, the exact magnitude of the problem in the country remains unknown.

The majority of the population consumes meat slaughtered and butchered in small local shops where the maintenance of hygiene is always questionable. Bangladesh has a few organized slaughterhouses mostly for export purposes, but the meat produced for the domestic market is sold as hot meat directly to the consumers from retail meat shops. The poor hygiene and sanitation prevailing in the abattoirs as well as the shops encourage microbial contamination, survival and growth. The higher microbial load in the shops is due to floor dressing and neglect of hygiene in contrast to the vertical rail dressing and hygiene maintenance adopted in the abattoir. The microbiological quality of meat and meat products is very important with regards to public health significance. There are several reports on outbreaks of food borne diseases because of consumption of meat (Lunden et al., 2003; Prakash et al., 2005; Bhandare et al., 2007). The meat is potentially 
subjected to contamination from a variety of sources within and outside animal during the slaughter of animal to sell. In living animals, those surfaces in contact with the environment harbor a variety of microorganisms. The contaminating organisms are derived mainly from the hide of the animal and the feces. The place of slaughter, the environment of the slaughter house, the floor of the retail outlet, the air in the outlet and the vehicle used for the transport of the meat from the slaughter house to the retail outlet act as the external sources for the contamination of the meat (Sofos et al., 1999 and Sudhakar et al., 2009). Food habits of Indian society have substantially changed due to rapid urbanization and westernization, resulting in people converting from vegetarian to non-vegetarian diet. Hence the demand for meat is increasing. Simultaneously the consumers have become more alert regarding the quality, freshness and health aspects of meat (Selvan et al., 2007). The absence of organized slaughter house facility and the existence of small retail outlets have been the two biggest hurdles for hygienic production of meat.

The public due to unawareness and due to nonenforcement of laws, many of a time, buy meat which cannot ensure protection to consumers from the effect of potential danger of inferior meat (Prodhan, 2015). Microbial implication in handling, slaughtering, dressing, processing and distribution of meat and meat products may endanger human health. Therefore the study was undertaken to determine the extent of microbial contamination of goat meat obtained from slaughter yards and from meat stalls at late market hours and to assess the selected microbial attributes such as total viable bacterial count (TVC), total coliform count
(TCC) and yeast mold count (YMC) in goat meat cuts of different sources. Thereby, the experiment was carried out with following objectives: i) to evaluate microbial load of goat meat during handling and selling in the market. ii) to examine the microbial load at different hours of interval from slaughtering to selling and iii) to recommend suitable time from slaughtering to selling.

\section{Materials and Methods}

\section{Place of experiment}

The experiment was conducted in the laboratory of the Department of Animal Science in Bangladesh Agricultural University (BAU), Mymensingh, Bangladesh. The experiment was conducted within JulyDecember 2014.

\section{Experimental samples}

All samples were obtained from local retail markets situated in K.R. Market at BAU campus, Sheshmore Market and Mymensingh City market. The markets were run by the local municipal authorities and upazila parishad. The goat of almost same ages were brought to convenient slaughter points and slaughtered by Halal method. After skinning they cut it into different parts of its body. Then the meat was put in sterilized bag. The samples were collected immediately after slaughter.

\section{Experimental design}

There are three treatments in this experiment. These are $\mathrm{T} 1=0$ hour (control), $\mathrm{T} 2=2$ hours, $\mathrm{T} 3=5$ hours. The bacterial count was taken at 0,2 , and 5 hours after the collection of the sample from each location.

\begin{tabular}{lcc}
\hline \multicolumn{1}{c}{ Samples } & No. of Replications & \multicolumn{1}{c}{ Treatments } \\
\hline Place 1 (KR Market) & 9 & $0 \mathrm{hr}$ (control), $2 \mathrm{hrs,} 5 \mathrm{hrs}$ \\
Place 2 (Seshmore) & 9 & $0 \mathrm{hr}$ (control), 2 hrs, $5 \mathrm{hrs}$ \\
Place 3 (Mymenshing city) & 9 & $0 \mathrm{hr}$ (control), 2 hrs, 5hrs \\
\hline
\end{tabular}

Media and reagent employed for TVC, TCC and YMC

\section{Solid media and reagents}

The media employed for these bacteriological analysis included plate count agar (PCA), MacConkey agar (MA) and potato dextrose agar (PDA). The commercial media were prepared according to the direction of the manufacturers.

\section{Glassware and other appliances}

Different types of glassware and appliances were used during the course of the experiment. These were as follows: Test tubes (with or without Durham's fermentation tube and stopper), petridishes, conical flask, pipette ( $1 \mathrm{ml}, 5 \mathrm{ml}, 10 \mathrm{ml}$ and $25 \mathrm{ml}$ capacities), glass rod spreader, test tube stand, mortar and pestle, whirly mixture machine, blender machine, water bath, incubator, refrigerator, sterilizing instruments, hot air oven, ice boxes, electronic balance.

\section{Preparation of sample for bacteriological studies}

Each of the samples was macerated in a mechanical blender using sterile diluents as per recommendation of International Organization for Standardizations (ISO, 1995). About ten grams of the meat sample was taken aseptically with a sterile forceps and transferred into sterile containers containing $90 \mathrm{ml}$ of $0.1 \%$ peptone water. A homogenized suspension was made in a sterile blender. Thus 1:10 dilution of the samples was obtained. Later on using whirly mixture machine different serial dilutions ranging from $10^{-2}$ to $10^{-7}$ were prepared according to the standard method (ISO, 1995).

\section{Enumeration of total viable count (TVC)}


For the determination of total bacterial count, $0.1 \mathrm{ml}$ of each ten-fold dilution was transferred and spread on duplicate PCA using a fresh pipette for each dilution. The diluted samples were spread as quickly as possible on the surface of the plate with a sterile glass spreader. One sterile spreader was used for each plate. The plates were then kept in an incubator at $37{ }^{\circ} \mathrm{C}$ for 24 hours. Following incubation, plates exhibiting $<300$ colonies were counted. The average number of colonies in a particular dilution was multiplied by the dilution factor to obtain the total viable count. The total viable count was calculated according to ISO (1995). The results of the total bacterial count were expressed as the number of organism or colony forming units per gram $(\mathrm{CFU} / \mathrm{g})$ of meat sample. Then results were calculated into log value.

\section{Enumeration of total coliform count (TCC)}

For the determination of Total Coliform Count (TCC), $0.1 \mathrm{ml}$ of each ten-fold dilution was transferred and spread on MacConkey agar using a sterile pipette for each dilution. The diluted samples were spread as quickly as possible on the surface of the plate with a sterile glass spreader. One sterile spreader was used for each plate. The plates were then kept in an incubator at $37^{\circ} \mathrm{C}$ for 24 hours. Following incubation, plates exhibiting $<300$ colonies were counted. The average number of colonies in a particular dilution was multiplied by the dilution factor to obtain the total viable count. The total viable count was calculated according to ISO (1995). The results of the total bacterial count were expressed as the number of organism or colony forming units per gram $(\mathrm{CFU} / \mathrm{g})$ of meat sample. Then results were calculated into $\log$ value.

\section{Enumeration of yeast-mold count (YMC)}

For the determination of yeast and mold counts, $0.1 \mathrm{ml}$ of each ten-fold dilution was transferred and spread on triplicate PDA agar using a sterile pipette for each dilution. The diluted samples were spread as quickly as possible on the surface of the plate with a sterile glass spreader. One sterile spreader was used for each plate. The plates were then kept in an incubator at $25^{\circ} \mathrm{C}$ for 48-72 hours. Following incubation, plates exhibiting 30-300 colonies were counted. Colonies were counted with the aid of a colony counter. The average number of colonies in a particular dilution was multiplied by the dilution factor to obtain the yeast and mold count. The yeast and mold count was calculated according to ISO (1995). The results of the yeast and mold count were expressed as the number of organism of colony forming units per gram $(\mathrm{CFU} / \mathrm{g})$ of goat samples.

\section{Statistical analysis}

All the average means and standard deviations were calculated through Microsoft excel. Microsoft Excel 2010 Data analysis tool pack was used to analyze the data. $3 \times 3$ factorial design was used to calculate the interaction between the place and time. One way anova from Microsoft Excel 2010 Data analysis tool pack was used to calculate the $P$ value.

\section{Results and Discussion}

\section{Total viable count (TVC)}

Total Viable count (TVC) is a measure of microbial quality of the meat. Presence of microbes in high numbers (TVC>10 7 CFU/g) first track the spoilage of the meat (Ahmad et al 2013). According to the raw meat Grading and Marketing Rules, APC of $60 \%$ of analyzed samples must not exceed $10^{6} \mathrm{CFU} / \mathrm{g}$, whereas $40 \%$ of the samples may have counts up to $10^{7} \mathrm{CFU} / \mathrm{g}$ (Mukhopadhyay et al., 2009). Results of TVC are placed in Table 1. Highest mean value for TVC in 0 hour found in Sessmore market but there were no significant difference in TVC among the markets assessed $(P>0.05)$. All the results of TVC at 5 Hours showed a gradual increase in TVC than 0 hour. Significant difference found among different hours in every cases $(\mathrm{P}<0.01)$. Initial counts show similarity with Hogue et al. 2008. This result shows that huge contaminations occur but there is more or less uniformity in bacterial load of these markets. However, the reduced counts on some cases are probably due in part to the fat layer which tends to reduce the amount of unbound moisture available for the growth or survival of microorganism (Jay, 1978 and Lasta et al., 1992) and also due to more exposure to washing. Increase in TVC with time shows similarity with Hassall (1995) where the study concluded that the bacterial count increased tremendously by the time the carcasses were received by the store from slaughter slab.

\section{Total coliform count (TCC)}

TCC indicates the hygienic condition of meat (Ahmad et al. 2013). According to Compendium of Microbiological Criteria for Food, 2016 coliforms more than $\log 2 \mathrm{cfu} / \mathrm{g}$ indicates unsatisfactory meat which may result pathogenic conditions from meat. The results of TCC are placed in Table 2. In present study, it revealed that, in many cases the TCC crossed the satisfactory level showing unhygienic conditions of the slaughter slabs and meat shops. At five hours all the samples crossed the satisfactory levels showing unacceptable meat in retail shops at late hours. Significant difference found among the markets at 0 hour $(P<0.05)$. Almost all cases significant difference found TCC level $(\mathrm{P}<0.05)$ with increase of time. Hoque et al. (2009) also found higher coliform counts in late hours at retail meat. Presence of some coliform bacteria may cause detrimental conditions and spoil the quality of meat and high count of TCC (more than $\log 2$ ) is not acceptable. Mukhopadhyay et al. (2013) and Bhandare et al. (2007) also found similar results in retail shops while detecting coliform bacteria.

\section{Yeast mold count (YMC)}

Yeast mold count can be used as an indicator of overall quality and safety of any food item. In many food 
standards it has been used such as food standards of Australia and New Zealand. Both yeasts and molds cause various degrees of deterioration and decomposition of foods. They can invade and grow on virtually any type of food at any time. In this study, the YMC count results are placed in Table 3. No significant difference found among the markets at 0 hours $(\mathrm{P}>0.05)$. But significant difference found at 2 hours and 5 hours in YMC among the markets $(\mathrm{P}<0.05)$. All the cases showed significant increase with time $(\mathrm{P}<0.01)$. Most of the experiments on yeast mold counts of meat show the satisfactory level of YMC $10^{2}-10^{3}$ cfu/g (Barros et al., 2007 and Huang et al 2014). In this experiment yeast mold count crossed satisfactory level in almost all the cases at 5 hours and were not satisfactory according to YMC level.

Table 1. Total Viable Count (TVC)

\begin{tabular}{lccccc}
\hline \multicolumn{5}{c}{ Time interval } & \multirow{2}{*}{ Significance level } \\
\hline Location & $\mathbf{0}$ hour & $\mathbf{2}$ hours & $\mathbf{5}$ hours & P value & $* *$ \\
KR Market & $4.33 \pm 0.45$ & $5.94 \pm 0.54$ & $6.92 \pm 0.21$ & 0.007 & $*$ \\
Shesmore & $5.24 \pm 0.42$ & $6.57 \pm 1.32$ & $8.09 \pm 0.50$ & 0.019 & $* *$ \\
Mymensingh City & $5.17 \pm 0.28$ & $6.64 \pm 0.05$ & $8.47 \pm 1.27$ & 0.004 & \\
P value & 0.214 & 0.539 & 0.128 & & \\
Significance Level & $\mathrm{NS}$ & $\mathrm{NS}$ & $\mathrm{NS}$ & & \\
\hline
\end{tabular}

$*=\mathrm{P}<0.05, * * \mathrm{P}<0.01$ and NS= Not Significant

Table 2. Total Coliform Count (TCC)

\begin{tabular}{lccccc}
\hline \multicolumn{5}{c}{ Time interval } & Significance level \\
\hline Location & $\mathbf{0}$ hour & 2 hours & 5 hours & P value & NS \\
KR Market & $2.2 \pm 0.31$ & $2.4 \pm 0.63$ & $2.73 \pm 0.41$ & 0.656 & $*$ \\
Shesmore & $1.41 \pm 0.01$ & $1.76 \pm 0.02$ & $2.36 \pm 0.17$ & 0.012 & $*$ \\
Mymensingh City & $2.63 \pm 0.09$ & $3.0 \pm 0.19$ & $3.50 \pm 0.05$ & 0.049 & \\
P value & 0.018 & 0.077 & 0.072 & & \\
Significance Level & $*$ & $\mathrm{NS}$ & $\mathrm{NS}$ & & \\
\hline
\end{tabular}

$*=\mathrm{P}<0.05, * * \mathrm{P}<0.01$ and NS $=$ Not Significant

Table 3. Yeast Mold Count (YMC)

\begin{tabular}{lccccc}
\hline \multicolumn{5}{c}{ Time interval } & \\
\hline Location & $\mathbf{0 ~ h r}$ & $\mathbf{2}$ hrs & $\mathbf{5}$ hrs & P value & Significance level \\
\hline KR Market & $2.42 \pm 0.10$ & $2.71 \pm 0.02$ & $3.42 \pm 0.13$ & 0.016 & $*$ \\
Seshmore & $2.36 \pm 0.02$ & $3.5 \pm 0.07$ & $4.12 \pm 0.17$ & 0.001 & $* *$ \\
Mymensingh City & $2.53 \pm 0.13$ & $3.33 \pm 0.26$ & $4.04 \pm 0.36$ & 0.002 & $* *$ \\
P value & 0.250 & 0.002 & 0.027 & & $*$ \\
Significance level & $\mathrm{NS}$ & $* *$ & $*$ & & \\
\hline
\end{tabular}

$*=\mathrm{P}<0.05, * * \mathrm{P}<0.01$ and $\mathrm{NS}=$ Not Significant

Interaction between place and time

No significant interaction was found between place and time. Similar results found in all places may be due to less difference among the places.

\section{Correlation}

The value of correlation coefficient between TVC and TCC were found $\mathrm{r}=0.41$ indicating weak relation between TVC and TCC. But Houqe et al. (2009) found strong relationship between TVC and TCC of beef. The value of correlation coefficient between TVC and YMC were found $r=0.87$ indicating relatively strong relation between TVC and YMC. This indicates there is relationship between TVC and YMC.

\section{Conclusion}

The study revealed that the microbial counts of different meat markets were very high and there were negligible difference between the microbial counts among the markets. At 0 hours the meat was in acceptable limits but at 2 and 5 hours most of the cases the bacterial counts crossed the acceptable limits. Therefore it is advisable to preserve the meat with care to avoid further microbial contamination after slaughter. However, it is vital for quality tools such as good manufacturing and hygiene practices, hazard analysis and critical control points, microbiological risk evaluation, and quality management to be integrated into the meat processing sector to get safe meat. It is also suggested that authorities should closely monitor and regulate proper slaughtering and transportation facilities in slaughterhouses and meat shops.

\section{References}

Ahmad, M.U.D., Sarwar, A., Najeeb, M. I., Nawaz, M., Anjum, A.A.,. Ali, M.A. and Mansur, N. 2013. Assessment of 
microbial load of raw meat at abattoirs and retail outlets. $J$. Anim. Plant S, 23(3):745-748.

Barros, M.F., Luís, A.N., Monteiro, A.A., Beloti, V. 2007. Identification of main contamination points by hygieneindicator microorganisms in beef processing plants.CiêncTecnol. Aliment. Campinas, 27(4): 856-862.

Bhandare, S.G., Sherikar, A.T., Paturkar, A.M., Waskar, V.S. and Zende, R.J. 2007. A comparison of microbial contamination of sheep/goat carcasses in a modern Indian abattoir and traditional meat shops. Food. Contr, 18: 854868.

Brahmbhatt, M.N. and Anjaria, J.M. 1991. Isolation of bacteria from market goat meat and their in vitro antibiotic sensitivity pattern. Indian J. Animal Sci., 63: 522-523.

Carlucci, A., Napolitano, F., Girolami, A. and Monteleone, E. 1999.Methodological approach to evaluate the effects of age at slaughter and storage temperature and time on sensory profile of lamb meat. Meat Sci., 52(4): 391-5.

Chowdhury, S.A. and Mutalib A. 2003.Goat production in Bangladesh present status and future programme. In: Goat production in SAARC countries, Afzal M and Usmani RH (eds). Pakistan Agricultural Research Council, Islamabad, Pakistan. pp. 628.

Dhanda, J.S. 2001.Evaluation of crossbred goat genotypes for growth, carcass and meat quality characteristics.PhD Thesis, University of Queensland, Australia.

DLS, 2016. Annual report, Department of Livestock Services, Bangladesh

Govindarajan, C.V. 1990. Maintenance of hygienic and sanitary conditions including personal hygiene in the meat factory. Technical paper in First National Seminar on Marketing of Meat Food Products in India, Aligarh. India.

Haque, M.A. ;Siddique, M.P., Habib, M.A., Sarkar, V. and Choudhury K. A. 2008. Evaluation of sanitary quality of goat meat obtained from slaughteryards and meat stalls at late market hours. Bangladesh. J. Vet. Med., 6 (1): 87-92.

Huang, R., Christopher, O.D., Hussain, M.A. 2014. Microbiological Quality of Selected Meat Products from the Canterbury Region of New Zealand. Int. J. Food Safety, 16:12-16.
ISO, 1995.International Organization for Standardization Protocol.

Jay, J.M. 1978. Modern Food Microbiology. D. Van Norstrand Co., New York. pp. 116-123.

Johnson, D.D., Estridge, J.S., Neubauer, D.R. and Mcgowan, C.H. 1995. Effect of sex class on nutrient content of meat from young goat.J. Anim. Sci., 73:296-301.

Lesiak, M.T.; Olson, D.G., Lesiak , C.A. and Ahn, D.U. 1997. Effects of postmortem time before chilling and chilling temperatures on water-holding capacity and texture of turkey breast muscle. J. Poul. Sci., 76: 552-556.

Lunden, J.M., Autio, T.J., Sjoberg A.M and Korkeala, H.J. 2003. Persistent and non-persistent Listeria monocytogenes contamination in meat and poultry processing plants. $J$. Food Protec., 66: 2062-2069.

Mukhopadhyay, H.K., Pillai, R.M., Pal, U.K. and Kumar, V.J.A. 2009. Microbial quality of fresh chevon and beef in retail Outlets of Pondicherry, Tamilnadu.J Vet.Ani Sci., 5 (1): 33-36

Prodhan, S.R. 2015. A study on hygienic and microbial aspects of goat meat in different slaughterhouses. MS Thesis. West Bengal University of Animal and Fishery Sciences.

Prakash, B., Krishnappa, G., Muniyappa, L. and Kumar, B.S. 2005.Epidemiological characterization of avian Salmonella entericaserovar infections in India. Int. J. Poultry Sci., 4 (6): 388-395.

Rahman, M.M. 2000. Fundamentals of Meat Hygiene. 'Bismillah' Farming and Frozen Meat Ltd. Dhaka, Bangladesh. pp. 76-101.

Selvan, P., Narendra, R., Babu, S., Sureshkumar, S. and Venkataramanujam, V. 2007. Microbial Quality of Retail Meat Products Available in Chennai city. American J. Food Techno., 2 (1): 55-59.

Sofos, J.N., Kochevar, S.L., Bellinger, G.R., Buege, D.R., Hancock, D.D., Ingham, S.C., Morgan, J.B., Reagan, J.O. and Smith, G.C. 1999. Sources and extent of microbiological contamination of beef carcasses in seven United States slaughtering plants. J Food Prot, 62(2):140-5. 